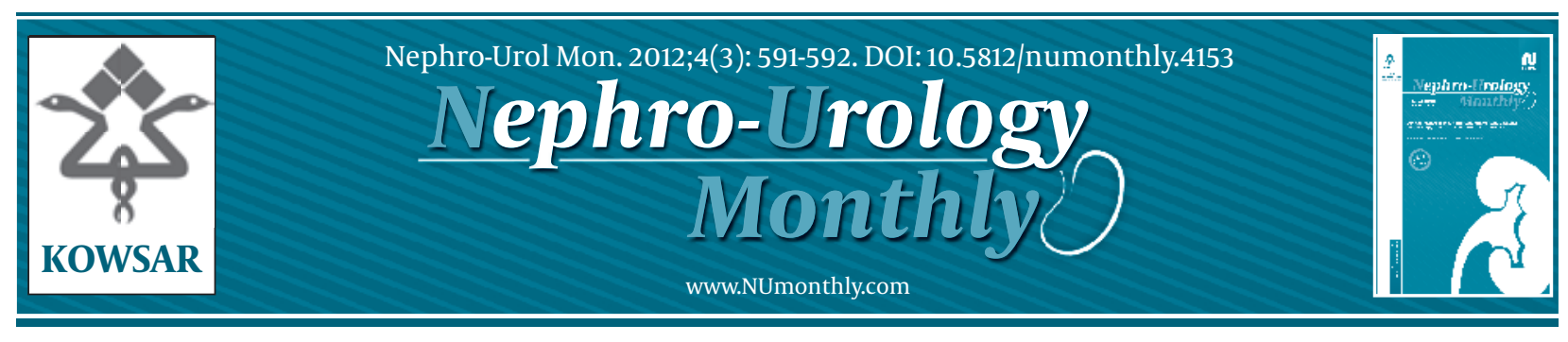

\title{
The Biofeedback Therapy in Patients With Stress Incontinence Urinary
}

\author{
Maria Thereza Micussi $1^{{ }^{*}}$ \\ ${ }^{1}$ Health Science Center, UFRN, Natal, Rio Grande do Norte, Brazil
}

\begin{tabular}{l}
\hline A R T I C L E I N F O \\
\hline Article type: \\
Letter to Editor \\
\hline Article history: \\
Received: 11 Jan 2012 \\
Revised:19 Jan 2012 \\
Accepted: 28 Jan 2012 \\
\hline
\end{tabular}

Keywords:

Therapeutics

Urinary Incontinence

\section{Dear Editor,}

I read with great interest the article by Seckiner et al. entitled "The Effect of Biofeedback Therapy on ICIQ-SF Scores and Urodynamic Parameters in Patients with Stress Urinary Incontinence" (1). The authors concluded that biofeedback therapy is capable of decreasing ICIQSF scores, that is, therapy improves symptoms and the impact of urinary incontinence on the patients' quality of life. Dumoulin et al. (2) showed that training pelvic floor muscles is effective in treating stress urinary incontinence (SUI) and this can be optimized when combined with biofeedback. On the other hand, Herdeschee et al. (3) suggested that women receiving biofeedback therapy are more likely to report that their urine loss was cured or improved, when compared to a group of women who had only undergone muscle training $(R R=0.75)$. Furthermore, in the authors' opinion, a urodynamic test is not necessary for patients who have submitted to biofeedback treatment. Although the gold standard for assessing SUI is a urodynamic examination, in addition to being costly, it is not well accepted by patients (4). Other methods, such as the pad test, are more accessible and

\footnotetext{
* Corresponding author: Maria Thereza Micussi, Health Science Center, UFRN, Natal, Rio Grande do Norte, Brazil. Tel: +55-8432121506, Fax: +558433429776,E-mail: therezamicussi@yahoo.com.br

DOI: $10.5812 /$ numonthly.4153

Copyright @2012 Kowsar Corp. All rights reserved.
}

\begin{abstract}
- Please cite this paper as:
Micussi MT. The Biofeedback Therapy in Patients With Stress Incontinence Urinary. Nephro-Urol Mon.2012.4(3): 591-2. DOI: 10.5812/numonthly.4153
\end{abstract}

Copyright $\odot 2012$ Kowsar Corp. All rights reserved.

have been used in clinical practice to assess, classify and quantify urinary losses $(5,6,7)$. The 1 -hour version is valid and recommended by the International Continence Society (8). Results show high specificity and sensitivity when compared with a urodynamic examination (9).

Another aspect discussed in the article is the need for exercise continuity at home. I am in total agreement with the authors, since exercises must be continued in order to avoid the emergence or worsening of symptoms. This matter should be emphasized more in studies, and include a description of the forms of patient adherence and incentives, especially over the long term.

\section{Financial Disclosure}

There is no financial disclosure.

\section{References}

1. Seckiner I, Erturhan MS, Erbagc A, Yagc F, Bayrak O. The Effect of Biofeedback Therapy on ICIQ-SF Scores and Urodynamic Parameters in Patients with Stress Urinary Incontinence. Nephro-Urol Mon. 2011;3(4):268-71.

2. Dumoulin C, Glazener C, Jenkinson D. Determining the optimal pelvic floor muscle training regimen for women with stress urinary incontinence. Neurourol Urodyn. 2011;30(5):746-53.

3. Herderschee R, Hay-Smith EJ, Herbison GP, Roovers JP, Heineman MJ. Feedback or biofeedback to augment pelvic floor muscle training for urinary incontinence in women. Cochrane Database Syst Rev. 2011(7):CD009252.

4. Housley SL, Harding C, Pickard R. Urodynamic assessment of urinary incontinence. Indian J Urol. 2010;26(2):215-20. 
5. Goepel M, Kirschner-Hermanns R, Welz-Barth A, Steinwachs KC, Rubben $\mathrm{H}$. Urinary incontinence in the elderly: part 3 of a series of articles on incontinence. Dtsch Arztebl Int. 2010;107(30):531-6.

6. Billington A. The management of stress urinary incontinence. $\mathrm{Br}$ J Nurs. 2010;19(18):S20-5.

7. Albuquerque MT, Micussi BC, Soares EM, Lemos TM, Brito TN Silva JB, et al. [Correlation between complaints of stress urinary incontinence and the one-hour pad test in postmenopausal women]. Rev Bras Ginecol Obstet. 2011;33(2):70-4.

8. Abrams P, Cardozo L, Fall M, Griffiths D, Rosier P, Ulmsten U, et al. The standardisation of terminology in lower urinary tract function: report from the standardisation sub-committee of the International Continence Society. Urology. 2003;61(1):37-49.

9. Paick JS, Ku JH, Shin JW, Park K, Son H, Oh SJ, et al. Significance of pad test loss for the evaluation of women with urinary incontinence. Neurourol Urodyn. 2005;24(1):39-43. 